Etnográfica

Revista do Centro em Rede de Investigação em

Antropologia

vol. $22(2) \mid 2018$

Vol. 22 (2)

\title{
Questões metodológicas de uma revisitação etnográfica a territórios psicotrópicos do Porto
}

Methodological aspects of an ethnographic revisitation of psychotropic territories in Oporto

\section{Simão Mata e Luís Fernandes}

\section{(2) OpenEdition}

Journals

Edição electrónica

URL: https://journals.openedition.org/etnografica/5443

DOI: 10.4000/etnografica.5443

ISSN: 2182-2891

\section{Editora}

Centro em Rede de Investigação em Antropologia

\section{Edição impressa}

Data de publição: 1 junho 2018

Paginação: 311-333

ISSN: 0873-6561

\section{Refêrencia eletrónica}

Simão Mata e Luís Fernandes, «Questões metodológicas de uma revisitação etnográfica a territórios psicotrópicos do Porto», Etnográfica [Online], vol. 22 (2) | 2018, posto online no dia 07 julho 2018, consultado o 20 janeiro 2022. URL: http://journals.openedition.org/etnografica/5443 ; DOI: https:// doi.org/10.4000/etnografica.5443

\section{(c) (7) (8)}

Etnográfica is licensed under a Creative Commons Attribution-NonCommercial 4.0 International License. 


\section{Questões metodológicas de uma revisitação etnográfica a territórios psicotrópicos do Porto}

\section{Simão Mata e Luís Fernandes}

Discute-se a metodologia de uma revisitação etnográfica realizada nos bairros do Aleixo, Pinheiro Torres e Pasteleira, na zona ocidental do Porto. As revisitações etnográficas caracterizam-se pela descrição e compreensão de um contexto sociocultural previamente estudado, procurando as aproximações e distâncias relativamente à pesquisa inicial. Uma breve revisão de algumas revisitações clássicas mostra como admitem várias modalidades. Aqueles territórios foram caracterizados através do trabalho de campo etnográfico (1990-1995) de um dos autores. Os atores e os territórios envolvidos nas atividades e sociabilidades em torno das drogas constituem-se, na revisitação iniciada em 2014, tal como na investigação inicial, no principal foco do trabalho de campo. O texto organiza-se a partir de três eixos: (1) breve revisão da literatura sobre as revisitações etnográficas, discutindo as suas implicações éticas, epistemológicas e metodológicas; (2) descrição dos procedimentos metodológicos acionados nesta pesquisa, salientando as dimensões técnicas e relacionais do trabalho de campo; (3) as limitações, potencialidades e desafios metodológicos que se relacionam com a pesquisa de terreno, em particular com as diferentes modalidades de "estar no campo". Por fim, são apresentadas algumas linhas temáticas emergentes, ao confrontar os dados trazidos até agora pela revisitação com a investigação inicial.

PALAVRAS-CHAVE: revisitação etnográfica, território, drogas, bairro social, trabalho de campo.

Methodological aspects of an ethnographic revisitation of psychotropic territories in Oporto - The article is focused on a methodological discussion of an ethnographic revisitation of Aleixo, Pinheiro Torres and Pasteleira neighbourhoods, in the western area of Oporto. Ethnographic revisitations imply describing and understanding a previously analysed sociocultural context, looking for differences and similarities relative to the initial research. A brief review of some classical revisitations shows that they encompass a range of operationalization modes. The authors' ongoing revisitation began in 2014, following one of the authors characterisation of these territories through ethnographic fieldwork (1990-1995). Current fieldwork, like the original one, is focused on the agents and territories involved in drug-related activities and interactions. The article is organised along three axes: (1) a brief review of the literature on the ethical, epistemological and methodological implications of ethnographic revisitations; (2) a description of the authors' research method, highlighting the technical and relational components of the fieldwork; (3) the limitations, advantages and methodological challenges related with fieldwork, particularly with the different modes of "being in the field." Finally, some of the themes that 
have so far emerged in the confrontation between the old and the new research data are approached.

KEYWORDS: ethnographic revisitation, territory, drugs, council estate, fieldwork.

MATA, Simão (simaomata@fpce.up.pt) - Centro de Ciências do Comportamento Desviante (CCCD), Faculdade de Psicologia e de Ciências da Educação, Universidade do Porto (FPCEUP), Portugal.

FERNANDES, Luís (jllf@fpce.up.pt) - Centro de Ciências do Comportamento Desviante (CCCD), Faculdade de Psicologia e de Ciências da Educação, Universidade do Porto (FPCEUP), Portugal.

AS REVISITAÇÕES ETNOGRÁFICAS SÃO UMA ESTRATÉGIA DE INVESTIgação que, embora pouco usual, tem já uma longa história na antropologia. As razões para a sua realização podem ser encontradas a partir, pelo menos, de dois interesses: o do desenvolvimento de teoria e do método em ciências sociais e humanas; o interesse pessoal do investigador. Sobre o primeiro destes dois interesses falará o texto que agora se apresenta, iniciando com a referência a revisitações etnográficas no campo da antropologia, algumas delas a terrenos que se tornaram quase míticos, constituindo uma espécie de património desta disciplina. Veremos como algumas destas revisitações confrontaram tal património, mostrando como no jogo de linguagem próprio da narrativa científica não há lugar para o imutável ou o cristalizado - a esta luz as revisitações são, em certa medida, dessacralizações. ${ }^{1}$ Sobre o segundo dos interesses - o do investigador - falaremos brevemente a seguir.

\section{ETNOGRAFIA NOS TERRITÓRIOS PSICOTRÓPICOS}

A investigação etnográfica em territórios psicotrópicos da zona ocidental do Porto, que temos em curso desde 2014, é a revisitação duma etnografia levada a cabo entre 1990 e 1995. Como veremos na secção seguinte, é próprio das revisitações serem realizadas ou pelo mesmo investigador, que regressa assim ao "seu" terreno, ou por um outro, que deliberadamente escolhe o terreno trabalhado pelo primeiro investigador alguns anos antes. Pois bem: o caso que temos em mãos - valha a metáfora, que fala ainda da etnografia como método quase artesanal... - é um misto da primeira e da segunda modalidades. É que

1 Inspiramo-nos em Lyotard quando, apoiando-se no conceito de jogo de linguagem de Wittgenstein, refere a ciência como uma das grandes narrativas da modernidade, constituída a partir dum jogo de linguagem específico (Lyotard 1979). 
um de nós realizou a investigação inicial, outro realiza agora a revisitação mas fá-lo em estreita ligação com o primeiro. ${ }^{2}$

Não desenvolveremos aqui o primeiro momento - o da investigação inicial. Falamos dele apenas para situar a revisitação atualmente em curso e remetemos os interessados, tanto no desenrolar desta primeira etnografia como no conceito que agora retomamos - o de "território psicotrópico" -, para os textos elaborados por Fernandes (1995, 1997, 1998, 2002a).

A investigação inicial prolongou-se por cinco anos. O tempo, ao longo dum trabalho de campo etnográfico, não é contínuo nem homogéneo: tem uma fase exploratória, tem outra intensiva, a saída não é decidida duma vez, muito menos com dia marcado. Entre estas fases e no decorrer delas há idas e vindas entre a unidade de estudo e outros contextos de vida do investigador, há momentos de grande imersão e momentos em que chega a parecer que o trabalho esmoreceu.

$\mathrm{Na}$ primeira investigação, a fase exploratória decorreu entre meados de 1990 e finais de 1991 e o bairro do Aleixo foi o núcleo da unidade de estudo (falaríamos agora, se isso não nos desviasse do que queremos dizer nesta secção, da pouca nitidez dos limites espaciais da unidade de estudo, da dificuldade em delimitar-lhe as fronteiras - por isso falamos em "núcleo"); a fase intensiva, durante a qual residimos no bairro Pinheiro Torres, decorreu entre outubro de 1992 e o verão do ano seguinte, com a maior parte do trabalho de campo no bairro da Pasteleira e frequente também no do Aleixo e no Pinheiro Torres; no final de 1993 e ao longo de 1994 começámos a espaçar a presença no terreno e o ano seguinte foi o da saída.

Importa deixar aqui testemunhada a vontade que sempre tivemos de regressar um dia ao "nosso" terreno. Onde inscrever esta vontade? Ficaria bem dizer que nos superiores interesses da ciência. Cartografar mudanças sociais numa "periferia degradada", inventariar permanências e alterações numa zona que, em 20 anos, conheceu vicissitudes como a construção de mais um bairro social, que é agora visto como o novo foco problemático, a demolição ainda incompleta de um outro - o mediático bairro do Aleixo - com o álibi da "guerra aos traficantes de droga”, o início da intervenção comunitária sistemática com populações vulneráveis e grupos estigmatizados, mas também na atenção às trajetórias de atores que conhecemos na investigação inicial, caracterizando as etapas e consequências das suas "carreiras nas drogas" - ou procurando o nexo à biografização, quer dizer, à expressão nas existências individuais das condições ecossociais da vida nos territórios psicotrópicos.

Mas inscrevemos a vontade do regresso também em algo mais pessoal. Sabem todos quantos fizeram trabalho de campo prolongado e envolvido que

2 Esta ligação é desde logo institucional: decorre do facto de ser o primeiro o orientador do segundo na realização do seu doutoramento, cujo objeto é precisamente a revisitação a territórios psicotrópicos da zona ocidental do Porto. 
não se sai dele igual ao que se era. Trata-se duma experiência transformante, pelo modo como exige (adaptações) e como confronta (as nossas grelhas prévias), como desafia (os nossos medos) e como provoca (o nosso engenho). Voltar ao terreno, então, para reencontrar sítios e pessoas, para relembrar momentos e sensações. Para nos reencontrarmos - porque a permanente atualização da pessoa que somos se faz também no reencontro com a memória das experiências fortes que vivemos. E, depois, esta curiosidade que não nos deixa parar e que nos impele a saber o que se passou com os "nossos" atores sociais e os sítios a que fomos também chamando "nossos" - porque o trabalho de campo é sempre uma apropriação de algo que de longe era estranho. Regressar, pois, aos lugares e atores, reencontrar familiaridades, sinalizar mudanças, ser surpreendido pelo que é novo e nos provoca agora estranheza.

Tínhamos, desde o momento da saída, a intenção de regressar um dia. Demorou mais de 20 anos. Mas, num dia de dezembro de 2014, o RS respondia à nossa chamada e comparecia pontualmente na sede da associação desportiva e recreativa do bairro. O informante privilegiado principal da etnografia inicial servia assim à passagem de testemunho, do primeiro investigador ao que agora chegava ao terreno, para realizar a revisitação. Retomaremos a figura do RS adiante.

\section{BREVE REVISÃO BIBLIOGRÁFICA SOBRE REVISITAÇÕES ETNOGRÁFICAS}

A primeira tarefa que se mostrava necessária, ainda antes da ida para o terreno, era a de adquirir uma visão panorâmica sobre o tema da revisitação etnográfica. A pesquisa bibliográfica que realizámos a tal respeito permite-nos destacar dois grandes conjuntos de trabalhos. Os primeiros correspondem a revisitações realizadas por um etnógrafo diferente daquele que estudou inicialmente determinado contexto de pesquisa. Estes estudos podem ser complementares à investigação inicial (e.g. Hutchinson 1996), atualizando os resultados ou os achados etnográficos iniciais; podem também assumir uma dimensão crítica em relação ao estudo prévio (Lewis 1963 [1951]; Pagán 1980; Freeman 1983).

A segunda categoria de revisitações diz respeito a trabalhos que foram realizados pelo mesmo etnógrafo, estudando-se em dois ou mais períodos temporais a mesma realidade sociocultural (Firth 1959; Colson 1960; Burawoy 1979; White 1993 [1943]; Cunha 2002). Daremos, já de seguida, destaque a cada uma das categorias a partir da revisão bibliográfica que efetuamos. A sistematização teórica e conceptual desenvolvida por Cunha (2014) sobre revisitações etnográficas serviu como bússola orientadora da pesquisa bibliográfica que realizámos. 


\section{Revisitações realizadas pelo mesmo etnógrafo}

Pela leitura do apêndice A de Street Corner Society, de William White (1993 [1943]), intitulado "On the evolution of 'street corner society'", em particular no capítulo 14, "Cornerville revisited", é possível constatar que o autor revisitou várias vezes a sua unidade de estudo - Cornerville, em Boston.

White (1993 [1943]) refere nesse apêndice da sua obra um conjunto de transformações urbanas e paisagísticas em Cornerville ao longo dos anos que refletem os processos de gentrificação que se podem encontrar na sua zona de estudo. De acordo com White (1993 [1943]: 342): "It was still predominantly an Italian-American district, but gentrification had set in." Dessas transformações destaca-se a demolição de estradas que permitiu a abertura para uma frente marítima. Esta situação favoreceu a instalação e o crescimento de atividades comerciais e de restauração na zona, bem como de novos parques habitacionais que não existiam na altura da sua etnografia inicial, em finais dos anos 30 do século XX.

A par dos processos de transformação e renovação urbana, a sua revisitação permitiu também destacar um conjunto de aspetos que permanecem semelhantes em relação à pesquisa inicial, realizada entre 1937 e 1940. Uma das semelhanças está na permanência física do local onde White ficou "instalado" durante a primeira investigação, perto do antigo restaurante Capri da família Orlandi, restaurante esse, contudo, já inexistente.

É também possível verificar que o encontro do investigador com Doc, o informante privilegiado da investigação inicial, foi marcado por algum desinteresse por parte deste relativamente a esse reencontro. White avança duas hipóteses para essa situação: "Perhaps Pecci had come to feel that i had gained fame and fortune throught Streer Corner Society, and he, who had provided the principal keys to that society, had not received his fair share of benefits" (White 1993 [1943]: 348). Mas outra explicação possível é também avançada: "Pecci had left the street corner so far behind that he no longer had any interest in connecting up with old times" (White 1993 [1943]: 348). Além disso, parece que o livro de White suscitou em Doc uma reação de afastamento pela origem académica do mesmo, desencorajando os restantes cornerboys da sua leitura: “No, you woudn't be interested, just a lot of big words. That's for the professors" (Whyte 1993 [1943]: 347). ${ }^{3}$

Continuemos ainda com as revisitações realizadas pelo mesmo etnógrafo. Mudemos, contudo, de espaço geográfico, situando-nos agora no continente africano. Elisabeth Colson, antropóloga norte-americana, revisita juntamente

3 Contudo, o autor não deixa de destacar o impacto que o seu livro Street Corner Society teve ao nível das estratégias interventivas locais, nomeadamente no plano da mobilização das populações caracterizadas e por a obra ter dado uma certa legitimidade académica a uma tendência não paternalista da intervenção (White 1993 [1943]). 
com uma colaboradora sua (Thayer Scudder), nos anos 70 do século XX, as comunidades de Gwembe (os "Gwembe Tonga people"), situadas entre a atual Zâmbia e o Zimbabué. ${ }^{4}$ Esta comunidade foi inicialmente caracterizada pela autora nos anos 40 do século XX, procurando compreender o impacto que as construções de larga escala na zona - nomeadamente a construção da central hidroelétrica no rio Kariba - tiveram na organização social destas comunidades. ${ }^{5}$ A autora destaca impactos ao nível da ansiedade e do stress nestas comunidades, gerados por essa mobilidade forçada. Segundo Colson: "When forcible removal involves also the destruction or consequent inaccessibility of that refuge, people suffer immensely, even those who left voluntarily but with the expectation that they could always return" (1989: 13).

Centremo-nos agora noutro continente, a Oceania. A revisitação do antropólogo neozelândês Raymond Firth (1959) procurou compreender as mudanças e as permanências ocorridas numa das comunidades da Polinésia - os tikópia ao longo do tempo, nomeadamente ao nível da sua organização social, da sua vida familiar e das relações de parentesco. Esta comunidade foi inicialmente estudada pelo autor em 1928 e 1929, sendo revisitada em 1952 e depois ainda em 1966. Os resultados das revisitações permitiram a Firth constatar que os tikópia se iam progressivamente abrindo, não só a outras comunidades da Oceania, mas sobretudo aos valores e costumes ocidentais - através daquilo a que o autor chamou "forças de modernização": no estudo inicial de Firth, os tikópia atribuíam particular importância às atividades sociais e religiosas (Firth 1936), enquanto que na revisitação Firth destacou o interesse pela tecnologia e pela arte decorativa nesta comunidade (Firth 1959).

Sztutman (1998), através de uma análise crítica das revisitações de Firth aos tikópia, refere como foi o confronto do autor após a sua segunda revisitação da comunidade estudada, tendo havido um período de cerca de 14 anos sem qualquer contacto: “Em vez da imagem edénica dos 'povos seminus', isolados em uma ilha da Polinésia, oferecida ao leitor logo nas primeiras páginas de Nós, os Tikopia, ele se deparava com um contexto de contato avançado com o 'mundo dos brancos', caracterizando, entre outras coisas, pela instalação da Igreja Anglicana" (Sztutman 1998: 245-246).

Até ao momento apresentámos revisitações etnográficas que se foram consagrando na história da antropologia em geral e da etnografia em particular num plano internacional. Mas também no plano nacional encontramos revisitações realizadas pelo mesmo investigador. A revisitação sociológica levada a cabo por José Madureira Pinto e colaboradores em Fonte Arcada (concelho de Penafiel) em inícios do século XXI permitiu destacar um conjunto de

4 De referir, contudo, que após a sua investigação inicial nos anos 40 do século XX, a autora revisitou várias vezes esta comunidade, sendo realizada a primeira revisitação em 1956 (Colson 1960).

$5 \quad$ Esta barragem foi construída entre 1955 e 1959. 
alterações significativas na comunidade estudada. Esta comunidade rural, caracterizada inicialmente na década de 70 do século XX, registava uma considerável ligação a diferentes instâncias socializadoras, tais como a família, a escola e a religião.

Estes temas foram precisamente aqueles que a revisitação, 30 anos depois, procurou compreender. A questão que orientou o trabalho da revisitação foi, por isso, a seguinte: "Confirmar-se-ão ou não, aqui, conhecidas tendências de um investimento crescente das famílias na escolarização dos mais jovens e de desinstitucionalização na esfera religiosa, com erosão das formas tradicionais de relação com o sagrado e com a Igreja?" (Pinto 2008: 12). A revisitação permitiu perceber um considerável nível de diferenciação interna nesta comunidade, algo que J. Madureira Pinto (2008) relaciona com alterações político-sociais ocorridas entre os dois períodos de investigação, nomeadamente "[...] pelo efeito conjugado da democratização do sistema político e da integração económica no espaço europeu, [...] por força de impulsos inéditos ao nível da escolarização das populações, da participação das mulheres nos mercados de trabalho, da presença dos media e das indústrias culturais no quotidiano da generalidade dos cidadãos" (Pinto 2008: 15).

A revisitação etnográfica de Manuela Ivone Cunha (2002) ao Estabelecimento Prisional de Tires é também um exemplo de uma revisitação realizada no contexto português pela mesma investigadora. Além da breve sistematização sobre as revisitações - e que funcionou, tal como se disse anteriormente, como guião orientador da nossa pesquisa bibliográfica -, Manuela Ivone Cunha explora ainda algumas questões metodológicas que se relacionam com a sua própria revisitação ao contexto de pesquisa - o Estabelecimento Prisional de Tires, estudado inicialmente em finais dos anos 80 e revisitado em finais dos anos 90 do século XX.

Tal como outros autores já salientaram a propósito das suas revisitações, as mudanças no seu contexto de pesquisa relacionaram-se com aspetos de composição da própria população revisitada. No caso da revisitação de Cunha (2002), foi saliente, no espaço de dez anos, uma alteração considerável na estrutura da população prisional. Isto teve como consequência uma abertura da sua pesquisa a novos contextos que não apenas a prisão. Assim, se o Estabelecimento Prisional de Tires continuava a ser o objeto de estudo, não se esgotava já nele a sua unidade de análise. ${ }^{6}$ As consequências metodológicas de tal conclusão acarretaram uma descentração do contexto prisional enquanto

6 A revisitação de J. Madureira Pinto (2008) a Fonte Arcada, a que fizemos atrás alusão, salienta também uma considerável mutação, não só no contexto estudado na primeira investigação, como também nas transformações sociológicas e científicas ocorridas no período que separa as duas pesquisas e que mudam "substancialmente o horizonte dos problemas a estudar e o conjunto de conceitos disponíveis para os enfrentar". Daí que, para o autor, "ficar agarrado exclusivamente a problemáticas que a anterior pesquisa suscitara constituiria uma inaceitável fuga à realidade” (Pinto 2008: 10). 
unidade analítica e a necessidade de abranger outros contextos de observação e pesquisa que se encontram na interface com a realidade prisional. O principal contexto de interface seria, de acordo com a autora, o bairro social periférico. Nas palavras de Cunha, "Em vez de um estudo prisional, tratava-se agora de um tricot a duas agulhas: o bairro e a prisão" (2014: 407).

Além das alterações no próprio terreno etnografado, o trabalho de Cunha (2002, 2014) salienta a importância dos fatores pessoais do etnógrafo que revisita o mesmo local de pesquisa. De forma muito resumida, se o terreno etnografado se altera com o tempo, o etnógrafo que o revisita apresenta também grelhas teóricas, pessoais e científicas distintas daquelas que possuía quando o caracterizou a primeira vez. Como refere Cunha, "É que uma investigação etnográfica é conduzida não apenas numa conjuntura interpessoal específica e num dado panorama teórico, mas também num momento do ciclo de vida do investigador e numa etapa da sua maturação intelectual e analítica" (2014: 410).

Assim, para Cunha, a questão da historicidade etnográfica deve ser sempre colocada quando se realiza uma revisitação. Para a autora, a revisitação relaciona-se, sobretudo, com uma tripla historicidade, relacionada com: as características e dinâmicas do terreno etnografado; a subjetividade do investigador e as suas características pessoais nos dois períodos de observação; e, finalmente, a evolução do próprio domínio teórico, conceptual e intelectual entre essas duas investigações. ${ }^{7}$

A modificação das grelhas teóricas, pessoais e científicas do etnógrafo ao longo do tempo deve relacionar-se, todavia, com o facto de a revisitação ser feita pelo mesmo etnógrafo ou por investigadores distintos. Diz-nos Cunha: "A questão da historicidade da pesquisa etnográfica não se coloca, de facto, da mesma maneira consoante uma investigação num dado terreno seja conduzida em diferentes momentos pelo mesmo investigador ou por etnógrafos diferentes (ver também, a este propósito, Burawoy 2003)" (Cunha 2014: 404-405). É exatamente sobre as revisitações realizadas por etnógrafos distintos que nos debruçaremos em seguida.

\section{Revisitações realizadas por etnógrafos distintos}

É neste tipo de revisitações que nos situamos, embora com a singularidade curiosa já referida: o investigador que realizou a pesquisa original participa na atual. ${ }^{8}$ Vejamos agora mais de perto algumas revisitações etnográficas que, apesar de tratarem temáticas e objetos distintos dos nossos, se pautam por

7 A esta tripla historicidade das revisitações etnográficas referida por Cunha (2014), Burawoy (2003) acrescenta uma outra dimensão: "pressão externa que é exercida sobre o terreno de pesquisa" (Burawoy 2003: 645).

8 A sua participação dá-se, não no papel de etnógrafo, mas no de orientador dos trabalhos de doutoramento nos quais a presente investigação se inscreve. 
desenhos e enfoques metodológicos próximos daqueles que temos vindo a realizar.

A investigação de Sharon Hutchinson (1996) é um bom exemplo de uma revisitação que visa complementar aspetos abordados na etnografia inicial. A autora estuda, nos anos 90 do século XX, os nuer do Sudão do Sul, cujos modos de vida foram caracterizados por Evans-Pritchard na primeira metade do século XX. Hutchinson vai tentar compreender como evoluíram esses modos de vida nesta comunidade entre 1930 e 1990. Percebe um aumento das variações culturais nesta comunidade, variações que diziam respeito à religião e ao género, entre outros aspetos, contrariamente àquilo que Evans-Pritchard verificara, nomeadamente a sua singularidade e pouca variabilidade interna. ${ }^{9}$

Mudando a geografia agora para os EUA, a fábrica Geer Company, em Chicago, estudada inicialmente por Donald Roy entre 1944 e 1945, foi revisitada por Michael Burawoy entre 1974 e 1975. Burawoy (2003) salienta uma alteração significativa relativamente àquilo que Roy constatou nesta fábrica 30 anos antes, particularmente a diminuição de relações verticalizadas entre a direção (management) e os empregados fabris, e o aumento de conflitos horizontais entre estes últimos, constatando mesmo um certo enfraquecimento da solidariedade e episódios de hostilidade entre os operários (Burawoy 1979). Ao tentar compreender como é que os processos de autoridade nesta fábrica evoluíram durante esse período de tempo, Burawoy parte das mesmas interrogações que o investigador inicial, estando a sua revisitação marcada por uma atenção a aspetos salientados por Donald Roy - aquilo que o autor apelida revisitação focada. Nas suas palavras, esta técnica etnográfica ocorre "when an ethnographer returns to the site of a previous study" (Burawoy 2003: 646).

Mas a análise bibliográfica permite-nos constatar que nem sempre as revisitações realizadas por diferentes etnógrafos assumem um caráter, diríamos, tão pacífico ou complementar como aquelas que temos analisado até aqui. Algumas revisitações são marcadas por uma forte crítica à etnografia inicial e, nalguns casos, mesmo pela negação/rejeição das conclusões do primeiro estudo. O trabalho de Derek Freeman (1983) é talvez o mais emblemático duma revisitação extremamente crítica relativamente à pesquisa inicial. A rejeição das conclusões de Margaret Mead a propósito dos rituais de passagem para a vida adulta nas jovens samoanesas leva Freeman (1983) a referir: "We have seen that the 'picture of the whole social life of Samoa' that Mead presented as an ethnographic background to her main conclusion in Coming of Age in Samoa is, in numerous respects, fundamentally in error". Freeman vai revisitar

9 Esta "mudança" na composição interna dos nuer no Sudão do Sul, constatada por Hutchinson e que difere na "unicidade" e "singularidade" verificada cerca de 60 anos antes por Evans-Pritchard, relaciona-se com uma das dimensões da historicidade das revisitações etnográficas que já mencionámos na secção anterior: as características e dinâmicas do próprio terreno etnografado (ver Cunha 2014). 
Samoa, na região da Polinésia, fazendo trabalho de campo no mesmo local onde Margaret Mead estudou os rituais de entrada na vida adulta por parte das jovens samoanesas. Recorreu também a algumas informantes de Mead que ainda se encontravam vivas. A crítica de Freeman a Mead diz respeito sobretudo às conclusões a que a autora chegou a propósito desses "rituais de passagem". A sua revisitação vem chamar a atenção para o facto de que todas as mulheres naquela comunidade se encontravam ao abrigo do sistema taupou, sistema esse que previa uma "virgindade institucionalizada" para as jovens mulheres e não apenas para as mulheres de alto estatuto social em Samoa, tal como defendia Mead. Além disso, as entrevistas que Freeman realizou às informantes de Mead ainda vivas não permitiram confirmar aquilo que estas tinham dito à autora; pelo contrário, negaram, por exemplo, ter estado envolvidas em sexo ocasional quando eram jovens e declararam mesmo a Freeman ter mentido a Mead sobre esse assunto.

O trabalho de Annette Weiner (1976) é também uma revisitação crítica de um trabalho etnográfico clássico, neste caso aos trobriandeses estudados por Bronislaw Malinowski (1961 [1922]). A autora revisita, nos anos 70 do século XX, o terreno estudado inicialmente por Malinowski entre 1915 e 1918, mostrando o papel ativo e a importância das mulheres das tribos trobriandesas na vida comunitária local. Segundo Bashkow: "Of the many critical reactions to Bronislaw Malinowski's classic work on the Trobriand Islands, one of the most ethnographically productive has been Annette Weiner's critique that Malinowski neglected the role of women in exchange" (2011: 9). De salientar ainda que também os etnógrafos que estudaram os trobriandeses além de Malinowski (e.g. Powell 1960) parecem ter omitido o papel ativo dos elementos do sexo feminino destas comunidades. Para Weiner, esta situação evidencia um viés de género no olhar etnográfico, tratando-se de uma "tendência androcêntrica" que não se limita apenas a este caso concreto da investigação nas ilhas Trobriand, mas à história da antropologia no seu todo; segundo Bashkow, Weiner teria assim por objetivo "to counter what she saw as an androcentric tendency deeply rooted in the history of anthropology" (Bashkow 2011 : 9).

Voltemos agora novamente ao continente americano, mas desta vez à América Central. Oscar Lewis (1963 [1951]) revisita Tepotzlán, uma comunidade mexicana, em dois períodos distintos (1943-1950, tendo ali permanecido vários meses, e 1956-1957). Contudo, essa comunidade tinha sido estudada em 1926-1927 por Robert Redfield. ${ }^{10}$ Por que assume a revisitação de Lewis uma postura crítica face às conclusões de Redfield? De acordo com Lewis, o primeiro investigador estudou esta comunidade mexicana com os referenciais

10 Este trabalho levou a que o autor obtivesse o seu doutoramento em Antropologia Sociocultural na Universidade de Chicago, publicando em 1930 a respetiva obra. 
ocidentais e sobretudo norte-americanos, não procurando aceder às representações, nomeadamente sobre a pobreza, a partir da lógica intrínseca aos habitantes de Tepotzlán. Hernández, a propósito da postura crítica de Lewis sobre a etnografia de Redfield, refere:

"Lewis consideró que el trabajo etnográfico de Redfield sobre Tepoztlán no arrojaba una mirada objetiva de la población, no abarcaba los problemas sociales, políticos y económicos de los habitantes y no proporcionaba el tema de la pobreza como a Lewis le interesaba: a través de lo que representa para el mexicano" (Hernández 2010: 50).

Desloquemo-nos agora para a Península Ibérica. Se recuarmos até a década de 70 do século XX, verificamos que Pagán (1980), antropólogo e nativo de Grazalema, ${ }^{11}$ vai estudar entre 1974 e 1979 a sua própria comunidade, situada em Cádis, na Andaluzia, com recurso ao método etnográfico. O estudo de Pagán vai permitir rejeitar as conclusões de Pitt-Rivers (1971 [1954]) a propósito de Grazalema, apesar de o trabalho do antropólogo britânico ser considerado por muitos como o primeiro estudo de antropologia social realizado em Espanha (Pagán 1980). Apesar do caráter pioneiro, destacam-se algumas fragilidades e falta de rigor metodológico na obra de Pitt-Rivers. Nas palavras de Pagán,

"The People of the Sierra está muy lejos de ser un modelo que sirva para analizar la realidad social española; es, pelo contrario, citando las palabras de un grazalemeño que leyó la edición española, 'un libro superficial que ha prejudicado a la cultura y a la historia del Pueblo'. El libro há presentado una imagen falsa de Andalucía y ha influído negativamente en estúdios históricos y antropológicos que se han realizado después" (Pagán 1980: 82).

Além de o livro de Pitt-Rivers espelhar uma "imagem falsa da Andaluzia", Pagán critica também a primeira investigação pela ausência de indicadores históricos sobre essa comunidade, afirmando a impossibilidade de compreensão de uma dada realidade sociocultural sem o recurso a esses dados.

Depois de feita esta breve revisão bibliográfica sobre os diferentes tipos e modalidades de revisitações etnográficas existentes, trataremos agora de tecer alguns considerandos metodológicos acerca da nossa revisitação aos territórios psicotrópicos da zona ocidental do Porto.

11 Trata-se de uma comunidade com cerca de dois mil habitantes. 


\section{ALGUMAS CONSIDERAÇÕES METODOLÓGICAS ACERCA DA NOSSA REVISITAÇÃO}

Para Caria, a etnografia é um lugar de fronteira que consiste em "estar dentro e estar fora dos contextos em análise e, simultaneamente, convocar os autóctones para se posicionarem do mesmo modo"; diz-nos ainda o autor que o etnógrafo "está dentro para compreender mas ao mesmo tempo tem que estar fora para racionalizar a experiência e poder construir um objeto científico legítimo" (Caria 2002: 13). É no quadro da "reflexividade etnográfica" (Caria 2002), enquanto processo de racionalização da experiência etnográfica, que salientamos alguns aspetos técnicos e relacionais que têm marcado o trabalho de campo desta revisitação, realizado por Simão Mata. Os primeiros correspondem às técnicas que temos de colocar em marcha para que a investigação se desenrole. Já os aspetos relacionais dizem respeito aos modos interativos, incluindo o envolvimento afetivo, entre nativos e etnógrafo. Os aspetos relacionais são, para Pina-Cabral (2000), a marca de qualquer pesquisa etnográfica.

\section{Aspetos técnicos}

A leitura do diário de campo da investigação inicial realizada por Luís Fernandes tem permitido identificar alguns núcleos temáticos da pesquisa inicial, que servem como orientadores das nossas incursões etnográficas. Essa leitura tem permitido também a identificação de alguns atores sociais que protagonizavam, no início dos anos 90, o fenómeno da droga nos territórios que agora revisitamos. Assim, a primeira etapa de pesquisa passou pela localização atual desses atores, nomeadamente o informante-chave da investigação inicial - o RS. ${ }^{12}$ Através dele, e de outros com quem nos temos relacionado, acedemos a outros atores sociais identificados a partir da leitura do diário da investigação inicial. Estes contactos têm aberto várias possibilidades: (1) conhecer a sua trajetória nos últimos 20 anos, possibilitando a recolha de dados sobre a evolução dos seus percursos como utilizadores de drogas e a evolução da relação com a matriz ecossocial em que decorrem as suas vidas; (2) aceder a representações e significados sobre o fenómeno da droga no âmbito da nossa unidade de estudo; (3) alargar o nosso quadro de relações dentro dessa unidade, possibilitando-nos o acesso a outros indivíduos, que permitirão por sua vez o acesso a novos grupos, sociabilidades e territorialidades.

O trabalho de campo iniciou-se em dezembro de 2014 e tem sido realizado em períodos de duas ou três tardes por semana, bem como noutros períodos

12 Mantemos o nome fictício com que o ator surge na investigação inicial. Como referido, o nosso primeiro contacto com ele foi realizado em dezembro de 2014, através do investigador que o conhecera anteriormente e que procedeu assim à "passagem de testemunho" - ou, mais literalmente, à passagem do informante privilegiado, que aceitou de imediato reassumir o papel na investigação presente. 
de um modo menos sistemático. Importa destacar uma experiência inicial e exploratória de Simão Mata, realizada entre outubro de 2009 e dezembro de 2013, enquanto técnico de redução de riscos e minimização de danos numa equipa multidisciplinar que faz trabalho de rua nalguns bairros que agora revisitamos - em particular o do Aleixo e o Pinheiro Torres. ${ }^{13}$ Essa experiência exploratória permitiu um primeiro conhecimento, quer sobre alguns aspetos que se relacionam com o fenómeno da droga nos territórios considerados, quer sobre alguns dos seus principais protagonistas (Mata e Fernandes 2016).

As secções do diário de campo do segundo investigador seguem de perto as que foram elaboradas pelo investigador inicial. ${ }^{14}$ Contudo, o caráter único, irrepetível e marcadamente subjetivo do trabalho etnográfico (Pina-Cabral 2000) fez com que o segundo investigador tivesse necessidade de acrescentar novas secções ao seu diário de campo: "atividade onírica", "secção pessoal", "conversas com informantes", "conversas com o Mister" e "notas diário Mister". ${ }^{15}$ Estas duas últimas secções marcam o caráter da investigação agora em curso enquanto revisitação, procurando estabelecer uma ligação metodológica com a pesquisa inicial. Além disso, as secções acrescentadas no diário do segundo investigador denunciam a sua matriz disciplinar de base - a psicologia -, procurando que contribuam para evidenciar e compreender algumas das suas dimensões psicológicas enquanto realiza o seu trabalho de campo. ${ }^{16}$

Quanto às técnicas mobilizadas ao longo da pesquisa de terreno, a observação, quer na modalidade participante quer na não participante, tem-se destacado como a técnica privilegiada de recolha de dados. O caráter progressivo dos relacionamentos no interior da unidade de estudo vai influenciando e marcando o estatuto do investigador nos contextos de pesquisa, variando entre momentos em que a sua identidade é referida (estatuto overt) até momentos em que é encoberta (estatuto covert) (Adler 1990). Temos também realizado entrevistas etnográficas (Spradley 1979) a alguns atores sociais, quer com os informantes-chave quer com outros elementos que o trabalho de campo tem mostrado ou venha a mostrar como relevantes, tendo como centro temático aspetos que se relacionam com o fenómeno da droga nos territórios psicotrópicos.

13 Trata-se da equipa de rua Rotas com Vida, da associação Norte Vida - Associação para a Promoção da Saúde.

14 Para a organização do diário do investigador inicial, ver Fernandes (2002b). O diário era então dividido nas seç̧ões "observações", "notas de terreno", "notas metodológicas", "fragmentos discursivos" e "fichas dos atores".

15 "Mister" foi o nome que o investigador deu no seu diário de campo ao primeiro etnógrafo.

16 A secção "atividade onírica" tem sido particularmente importante na revelação de situações e dilemas que o trabalho de campo tem trazido ao investigador, que, desde o seu início, aí tem registado um conjunto de sonhos sobre os atores sociais, sobre os territórios considerados e sobre o objeto de estudo. Encontra-se em alguns trabalhos esta utilização dos sonhos como "ferramentas/instrumentos" de análise etnográfica, sejam os do próprio investigador (Yarlykapov 2007) sejam os dos nativos de determinada realidade sociocultural (Tobón 2015; Zivkovic 2006). 
Desde o início da pesquisa do segundo investigador, a técnica do "go-along" (Kusenbach 2003) pelos territórios com os informantes-chave tem-se revelado de grande utilidade. Tem sido realizada quer na modalidade de "walk-alongs", quando a realizamos a pé na companhia de algum(ns) nativo(s), quer na de "ride-alongs", quando a realizamos através do automóvel (neste caso, "caralongs"). Para Kusenbach:

"When conducting go-alongs, fieldworkers accompany individual informants on their 'natural' outings, and - through asking questions, listening and observing - actively explore their subjects' stream of experiences and practices as they move through, and interact with, their physical and social environment" (2003: 463).

Esta técnica, ao permitir a circulação por diferentes zonas de uma realidade sociocultural, permite diversificar as formas de se "estar no terreno", contribuindo para que a pesquisa não se fixe apenas num ou em poucos ponto(s) concreto(s) e "se desloque/mova" a partir das orientações dos informantes. Recorrendo novamente às palavras de Kusenbach, usamos o " 'go-along' as an ethnographic research tool that brings to the foreground some of the transcendent aspects of lived experience as grounded in place" (2003: 456).

Além da técnica do "go-along", temos ainda ensaiado incursões nos territórios sem a companhia de qualquer ator social. Chamámos-lhes, a dado momento no nosso diário de campo, "go-alone", uma vez que a incursão é feita a sós. O principal objetivo desta técnica é o (re)conhecimento dos limites dos territórios e dos atores à nossa presença, percebendo com isso os nossos próprios limites enquanto realizamos o trabalho de campo. Permite-nos perceber ainda até que ponto é que estamos ou não inseridos na nossa unidade de pesquisa e em que medida nos sentimos confortáveis quando nos deslocamos sozinhos pelos territórios.

Temos ainda utilizado técnicas que são complementares destas, nomeadamente a recolha de documentos sobre os atores e os territórios (por exemplo, textos escritos pelos "nativos", artefactos que produzam...), bem como de notícias/peças jornalísticas acerca dos atores e territórios. Temo-nos socorrido, também, da fotografia como técnica de recolha de dados, captando imagens sobre a zona de estudo. Esta utilização da imagem fotográfica tem sido complementar da dimensão verbal utilizada pelos atores sobre esses espaços e do nosso próprio registo escrito sobre os mesmos. ${ }^{17}$

17 As leituras que temos realizado sobre a utilização da imagem fotográfica na etnografia têm-nos permitido constatar a complementaridade e o diálogo que a fotografia pode estabelecer com outras técnicas de recolha de dados empíricos. Boni e Moreschi (2007), a propósito da utilização da fotografia por parte de Bronislaw Malinowski nos Argonautas do Pacífico Ocidental, refere que "fica patente que, para Malinowski, o verbal e o pictórico (desenhos, esquemas e fotografias) são cúmplices [continua] 


\section{Aspetos relacionais}

Paralelamente aos aspetos técnicos referidos na secção acima, surgem também no nosso trabalho de campo alguns aspetos relacionais que importa destacar. Esses aspetos relacionam-se com o envolvimento pessoal do etnógrafo com os nativos e com os territórios de estudo. Segundo Pina-Cabral:

"Whether this is done [ethnography] through some form of "participant observation' or by any other of the many qualitative methods that have since then been tried out, I believe that it is only useful to call a research ethnographic if the researcher is somehow personally involved in the field" (2000: 343).

Este envolvimento tem-se revelado na nossa pesquisa uma fonte de enormes contradições e complexidades. Os contextos em análise, marcados pelo sofrimento social, pela invisibilidade e pela hiperestigmatização (Fernández González 2014), convocam-nos ao longo do trabalho de campo dilemas, confrontos e exigências pessoais que importa problematizar. Se esses confrontos e exigências podem, por um lado, potenciar o interesse e a curiosidade do etnógrafo no conhecimento das dinâmicas locais da unidade de estudo, podem também, se não forem devidamente enquadradas e racionalizadas, dificultar o trabalho de campo. ${ }^{18}$

A relação entre etnógrafo e "nativos" apresenta, como aliás qualquer relação humana, um caráter progressivo ao nível do interconhecimento dos intervenientes. Mas essa relação comporta regras e limites que convém conhecer e respeitar, para que não se comprometa a presença do investigador no setting e se potenciem os relacionamentos com os "nativos". Alguns desses requisitos são a confiança, a transparência e a autenticidade. A propósito da autenticidade entre nós e os atores sociais, o nosso informante privilegiado principal (relembremos que é RS, o mesmo da investigação inicial) disse-nos algo que traduz a sua importância. Conversávamos sobre como iríamos "ter acesso" e desenvolver relacionamentos numa zona de venda de drogas. Ele disse-nos simplesmente: "Seres mais tu para seres um deles" [diário de campo, secção "anotações metodológicas", 4 de abril de 2015]. Apontava também para o caráter progressivo que deveria assumir a nossa inserção nestes espaços. Disse-nos ainda que a nossa presença deveria ser marcada, numa fase inicial, por

necessários para a elaboração de uma antropologia descritiva aprofundada. [...] O texto não basta por si só. A fotografia, também não. Acoplados, inter-relacionados constantemente, então sim, ambos proporcionarão o sentido e a significação" (Boni e Moreschi 2007: 143).

18 Ver, a este respeito, "O antropólogo e os pobres: introdução metodológica e afetiva", introdução à obra A Máquina e a Revolta, em que Alba Zaluar (1985) reflete sobre o modo como o olhar do antropólogo pode ser afetado pelas imagens construídas mediaticamente sobre um conjunto urbano estigmatizado e habitado por "gente perigosa". 
uma "interação presencial" nestes contextos que, com o passar do tempo, daria lugar a uma "interação comunicativa" com os atores. ${ }^{19} \mathrm{O}$ objetivo principal desta interação passa pelo "ser visto ali", como disse o RS, procurando que os "nativos" nos vejam naquele contexto como alguém que não coloca em causa o normal curso das atividades e das interações sociais. ${ }^{20}$

Em suma, estas duas modalidades interativas, crescentes em intensidade relacional, correspondem a formas de "estar no terreno" que exigem diferentes posturas por parte do etnógrafo. $\mathrm{Na}$ "interação presencial" procura-se uma postura passiva, de contactos mínimos ou superficiais. O etnógrafo observa sobretudo aquilo que o(s) informante(s) faz(em) com os outros "nativos", assiste de forma passiva às conversas que ali são estabelecidas, recolhe as primeiras representações da comunidade, espera que o(s) informante(s) o apresente $(\mathrm{m})$ aos elementos da comunidade, fazendo-se com isso presente nos contextos. Já na "interação comunicativa" procura-se uma postura ativa, ganhando-se, com o tempo, alguma autonomização ao nível das interações no terreno. O etnógrafo integra-se progressivamente com os atores em copresença e vai sendo capaz de interagir de forma mais envolvida.

Com o passar do tempo e a respetiva maior facilidade em criar momentos de "interação comunicativa", conceptualizamos aquilo que no nosso diário de campo designamos como "entradas não planeadas". Queremos com isto dizer que, se numa fase inicial de aproximação a estes espaços e atores planeávamos com rigor as nossas entradas nestes espaços, com o adquirir de autonomia - desde logo em relação ao(s) informantes(s) -, optamos por não planear a altura ou o dia em que nos deslocamos aos mesmos. Além disso, o facto de irmos para o terreno sem planeamentos prévios tem contribuído para diluir a nossa presença nos territórios considerados, diminuindo com isso a sensação de "corpo estranho" ou os "efeitos de contraste" entre nós e os "nativos". Escrevíamos assim no diário, após uma deslocação não planeada:

"Vou ter com eles sem dizer nada que ia. Fui levar a S. às Antas e aproveitei para passar por lá pela Pasteleira, para fazer um bocado de conversa com o pessoal. Não foi algo que estivesse previamente planeado, nem para eles nem para mim. Reparei que este 'efeito surpresa' teve um efeito positivo

19 "Interação presencial" e "interação participativa" são os termos do próprio ator social referidos no nosso diário de campo em 12/03/2015.

20 A "interação presencial" de que demos conta não se afasta daquilo que temos lido nas reflexões metodológicas de outras etnografias no que diz respeito à inserção nos contextos de pesquisa. William White (1993 [1943]), por exemplo, destaca que, na altura em que se inseria num ambiente de jogo no seu contexto de pesquisa, foi levado inicialmente e apresentado pelo seu informante privilegiado, Doc, como "my friend Billy"; diria White que nesta altura apenas escutava com interesse as interações entre os jogadores e o seu informante privilegiado, tinha uma atitude de escuta passiva ainda que tentasse agir também de forma amigável e com interesse. 
neles, principalmente quando thes expliquei o caráter de ter ido ali. Isso permitiu-lhes perceber que: 1. Eu os encaro como fazendo parte do meu quotidiano normal, encontrando-se inscritos na minha vida, tentando não separar o meu quotidiano do deles. É como se a minha vida privada fosse uma continuidade do quotidiano deles e vice-versa, não os fazendo perceber tanto a descontinuidade e a barreira que em todo o caso e para todos os efeitos existe entre mim e eles. 2. Deu-lhes uma sensação de recetividade da minha parte, revelando-me menos passivo na busca do conhecimento e mais ativo na procura deles, na entrada nos seus contextos de interação sem ter 'planeamentos' prévios. Notei isso fundamentalmente no RS, que ao me ver ali ficou simultaneamente admirado e, posso dizer com a subjetividade que a palavra implica, de certa forma feliz em me ver de forma inesperada" [diário de campo, secção de “anotações metodológicas”, 24 de março de 2015].

Por outro lado, este ganho de autonomia relacional deve ainda pautar-se pela incorporação na nossa linguagem dos termos ou expressões linguísticas que marcam as interações entre os atores locais. Consiste, segundo Fernandes, Neves e Chaves, na "familiarização com a gíria local", dando uma "impressão de realidade' no interlocutor, procurando, com isso, gerar um sentimento de confiança relativamente a si" (2001: 191). ${ }^{21}$ No mesmo sentido, Firmino da Costa refere: "Se [o investigador] não conhecer a língua, ou as regras de trânsito, ou se não se vestir duma das maneiras ali habituais - para só mencionar alguns dos mais óbvios duma multidão de requisitos - o [...] impacto arrisca-se a ser muito maior" (Costa 1986: 135).

A passagem da "interação presencial” à "comunicativa” teve no RS um elemento decisivo - como foi também decisivo enquanto elo de continuidade entre a primeira investigação e a revisitação atual, já que se trata do mesmo ator que também com o primeiro etnógrafo desempenhou o papel de informante privilegiado principal. O RS era, nessa altura, um morador do bairro em que se situava um dos principais territórios onde foi desenvolvido trabalho de campo. Chegámos ao seu conhecimento através de um amigo que vivia no bairro desde o seu início (em 1960) e que nos disse "conhecer a pessoa certa" para nos aproximar dos atores e territórios psicotrópicos. O RS tinha na altura 32 anos - tem agora 59 - e tinha saído poucos meses antes do estabelecimento prisional onde cumprira uma pena de quatro anos por tráfico de drogas. Tinha também um longo percurso como utilizador de várias drogas

21 Os autores chamam a atenção para o efeito indesejável dessa situação: "É importante, no entanto, acrescentar que se o investigador não incorporar suficientemente algumas 'formas de apresentação' e 'estilos' específicos da população estudada, fazendo com que a 'representação' surja pouco credível e grotesca aos olhos desses observados que o observam e que com ele interagem, mais valerá que não desenvolva estes esforços miméticos, pois poderá, inversamente, colher efeitos contraproducentes" (Fernandes, Neves e Chaves 2001: 191). 
e uma interação fácil com muitos atores locais envolvidos nas atividades psicotrópicas. ${ }^{22}$

Luís Fernandes contactou agora de novo o RS, inquirindo da sua disponibilidade para ajudar o etnógrafo que faria a revisitação. O RS continua a viver no mesmo bairro, mas noutro bloco de habitação, e a ter inserção nas redes de sociabilidade locais, embora já afastado dos consumos de drogas e com distância social em relação à geração mais jovem envolvida nas cenas psicotrópicas de rua. Mesmo assim, o seu papel voltou agora a ser decisivo na inserção inicial do investigador, acelerando o conhecimento dos atores e atividades do contexto que permitiria progressivamente evoluir no trabalho de campo já sem a intermediação do RS.

\section{PRIMEIROS RESULTADOS E NOVAS PISTAS DA REVISITAÇÃO}

Como já referimos na secção anterior, a segunda investigação teve uma fase exploratória que decorreu entre 2009 e 2013 no bairro do Aleixo e no Pinheiro Torres. Não havia nessa altura ainda a ideia explícita da revisitação, que só viria a ser claramente intencionalizada a partir de 2014, altura em que se iniciou a fase intensiva agora em curso. É prematuro portanto estar a avançar resultados, tanto do terreno atual como os resultantes do exercício de comparação com a investigação inicial. ${ }^{23}$

Mesmo assim, apresentam-se em seguida alguns dados que constituirão grandes temas em análise na monografia final, começando no contexto mais geral, passando pelos territórios psicotrópicos e chegando até aos atores sociais.

Que permanências e alterações podemos assinalar no espaço ecossocial em que se insere a nossa unidade de estudo? Dizia-se na primeira investigação tratar-se duma zona da cidade marcada por grandes assimetrias sociais, gerando uma forte visibilidade do contraste entre "bairros degradados", de que o ícone mediático era o do Aleixo, e zonas residenciais de alto estatuto. Esta assimetria parece ter-se acentuado nestes últimos 20-25 anos, com a construção de condomínios fechados na vizinhança de alguns dos sete bairros camarários da zona e com a finalização e povoamento de um novo bairro social, que estava em construção na altura da primeira investigação e que adquiriu em pouco tempo já o estatuto de "problemático". Este bairro, tal como os da Pasteleira e o Pinheiro Torres, está encostado aos muros da Quinta de Serralves, que alberga o Museu de Serralves e, desde a investigação inicial até agora, reforçou o seu estatuto de ícone cultural e turístico do Porto.

22 Em O Sítio das Drogas (Fernandes 1998), o seu papel na primeira etnografia encontra-se amplamente ilustrado.

23 Remetemos para Mata e Fernandes (2016), onde são já referidos alguns resultados da atual investigação. 
Entretanto, continuaram a encerrar as poucas unidades fabris que persistiam, tendo-se transformado uma delas, que fecha o bairro Pinheiro Torres pelo lado sul, num território psicotrópico com alojamento permanente no seu interior em ruínas. Este território permitiu observar em ação duas políticas de cidade de sinal contrário: a da redução de riscos e minimização de danos, protagonizada pelos técnicos que diariamente paravam a carrinha defronte da fábrica; e a securitária, protagonizada pelas intervenções policiais, culminando numa ação higienista decidida pelo poder municipal e que entaipou a fábrica, impedindo temporariamente o acesso ao seu interior por parte dos toxicodependentes.

Se estruturas abandonadas deste tipo proporcionaram o suporte espacial para os novos territórios psicotrópicos, os que conhecemos de há duas décadas mantêm o seu funcionamento, por vezes com pequenas deslocações, respondendo a pressões do "combate à droga". A mobilidade que os caracteriza e de que Luís Fernandes deu conta há 20 anos vai deslocando os seus "hotspots" de um bloco habitacional para outro, de uma esquina ou de um terreno baldio para outro, mas mantendo-os sempre dentro de um mesmo perímetro, que tem nos três bairros referidos os seus vértices. $\mathrm{O}$ novo bairro, entretanto construído, veio reforçar esta atividade psicotrópica, tendo hoje ao nível das instituições de controle e da comunicação social o estatuto de novo foco problemático. ${ }^{24}$

Por outro lado, a decisão da autarquia portuense de demolir o bairro do Aleixo, implodindo a primeira das cinco torres em dezembro de 2011 , não se cumpriu integralmente. Há ainda duas torres habitadas, uma vazia à espera da implosão e duas já demolidas. O Aleixo está agora com o seu espaço como que esventrado, com terrenos ocos no lugar das antigas torres, tendo precarizado ainda mais um habitat já etiquetado pela cidade com adjetivações negativas. O argumento político que legitimou a decisão de banir este bairro do mapa da cidade girou em torno da sua irremediabilidade, pois apresentava um conjunto de problemas entre os quais avultariam as atividades criminais em torno das drogas - um "bairro de tráfico", com toda a delinquência conexa a esta economia ilegal. Pois bem: a demolição começou no lado oposto ao do principal ponto de comércio das drogas, que continua a funcionar sensivelmente com as mesmas características e movimento que tinha antes do início da operação urbanística, com vendedores, angariadores de clientes ("capeadores"), vigias, compradores, compradores-consumidores no local, visitas diárias dos técnicos de redução de riscos e visitas frequentes das forças policiais.

24 Este bairro recebeu uma parte dos habitantes realojados devido à demolição dum outro conjunto de habitação social, o São João de Deus, ocorrida entre 2002 e 2006 e para a qual o argumento legitimador por parte do poder autárquico foi "o tráfico e intenso consumo de droga". Para a caracterização do impacto dessa operação urbana, ver Fernandes e Ramos (2010). 
Uma diferença importante em relação à investigação inicial diz respeito à presença de equipas de redução de riscos e minimização de danos em territórios psicotrópicos em dois dos três bairros onde decorreu no passado e decorre agora o nosso trabalho de campo. Trata-se do resultado prático de "diagnósticos territoriais" efetuados pelo Instituto da Droga e da Toxicodependência no início deste milénio, que decidiu desse modo prioridades no financiamento de equipas de rua multidisciplinares que deveriam atuar nas zonas onde o "problema da droga" mostrava maiores consequências para a saúde pública e a (des)ordem urbana. ${ }^{25}$

A chegada destas equipas ao "nosso" terreno foi, digamos, a confirmação oficial do estatuto destas zonas como as mais emblemáticas do "problema da droga", reiterando, se necessário fosse, a pertinência da nossa unidade de estudo em relação ao objeto que queríamos investigar. Por outro lado, tal chegada lançou também novas pistas de investigação, que por agora resumimos em duas questões: (1) Como falam os nossos sujeitos desta presença de técnicos no "seu" território? Como se relacionam com eles? Que utilidade (ou falta dela) lhes detetam? (2) A diminuição do consumo de heroína, sobretudo através da forma injetada (dado recorrente nos últimos anos, reportado pelo relatório anual elaborado pelo Instituto da Droga e da Toxicodependência), tem relação com o trabalho de proximidade realizado pelos técnicos de redução de riscos? Ou trata-se de um efeito de autolimitação, espécie de curva "natural" da evolução de uma droga, como alguma literatura refere?

Finalmente, centremo-nos no plano dos atores, registando também a este nível permanências e mudanças. A permanência mais notória é, desde logo, a do informante-chave principal da primeira investigação - agora inevitavelmente com mais 20 anos - e, circunstância que ainda não descortinámos noutra revisitação por agora, o facto de estar a desempenhar esse mesmo papel no atual trabalho de campo. Para além dele, foi já possível localizar e recolher testemunhos de outros atores sociais que vêm desse tempo. Outra permanência é a do assistente social da Junta de Freguesia que serve estes bairros, cujo testemunho importará também recolher.

Um dado que, tanto como o das permanências, abre uma importante pista de investigação é o das ausências. Com efeito, vários dos atores do início dos anos 90 faleceram, tendo um dos óbitos ocorrido já depois de iniciada a revisitação. Porque morreram indivíduos que estariam agora na casa dos 50 anos, um ou outro já na dos 60? Importa saber como foi a trajetória destes utilizadores de drogas e como se relaciona com estas mortes prematuras; importa saber o que revelam, para além do plano individual, do contexto ecossocial

25 Foi precisamente numa destas equipas, tal como já referimos, que o atual investigador teve os primeiros contactos com estes territórios, iniciando aí registos observacionais que deram corpo à fase exploratória da revisitação. 
em que decorreram as suas vidas. Lançam assim, com o seu desaparecimento precoce, uma nova pista de investigação: a desigualdade em relação ao centro reflete-se também na saúde? O periférico é uma condição limitadora do acesso aos recursos, desde logo aos da saúde? Como opera no concreto das vidas dos indivíduos periferizados esta limitação em tal acesso? Lembram-nos estas questões o "suffering body of the city", expressão com a qual Le Marcis (2004) propõe a cidade como corpo enquanto metáfora espacial dos próprios corpos dos indivíduos, também eles distribuídos segundo uma relação desigual centro-periferia.

A investigação atualmente em curso seguirá assim os núcleos temáticos sugeridos pela leitura do diário do investigador inicial, mas abre também novas direções, como as que fomos exemplificando ao longo desta secção. Porque, no trabalho de campo etnográfico, o terreno é generativo e a investigação deve ter a capacidade de se renovar por dentro - mesmo quando aparentemente "só" foi revisitar.

\section{BIBLIOGRAFIA}

ADLER, Patricia, 1990, "Ethnographic research on hidden populations: penetrating the drug world", em Elizabeth Y. Lambert (org.), The Collection and Interpretation of Data from Hidden Populations. Rockville, MD, National Institute on Drug Abuse, 96-1 12.

BASHKOW, Ira, 2011 , "Old light on a new controversy: Alex Rentoul's account of the Trobriand women's sagali”, History of Anthropology Newsletter, 38 (2): 9-18.

BONI, Paulo, e Bruna MORESCHI, 2007, "Fotoetnografia: a importância da fotografia para o resgate etnográfico", Doc On-line, 3: 137-157.

BURAWOY, Michael, 1979, Manufacturing Consent. Chicago, The University of Chicago Press.

BURAWOY, Michael, 2003, "Revisits: and outline of a theory of reflexive ethnography", American Sociological Review, 68 (5): 645-679.

CARIA, Telmo, 2002, "A construção etnográfica do conhecimento em ciências sociais: reflexividade e fronteiras", em T. Caria (org.), Experiência Etnográfica em Ciências Sociais. Porto, Afrontamento, 9-20.

COLSON, Elisabeth, 1960, Social Organization of the Gwembe Tonga. Manchester, Manchester University Press.

COLSON, Elisabeth, 1989, "Overview”, Annual Review of Anthropology, 18: 1-16.

COSTA, António Firmino da, 1986, "A pesquisa de terreno em sociologia", em A.S. Silva e J. M. Pinto (orgs.), Metodologia das Ciências Sociais. Porto, Afrontamento.

CUNHA, Manuela Ivone, 2002, Entre o Bairro e a Prisão: Tráfico e Trajectos. Lisboa, Fim de Século. 
CUNHA, Manuela Ivone, 2014, "Linhas de redefinição de um objeto: entre transformações no terreno e transformações na antropologia”, Etnográfica, 18 (2): 403-413.

FERNANDES, Luís, 1995, “O sítio das drogas: etnografia urbana dos territórios psicotrópicos”, Toxicodependências, 2: 22-32.

FERNANDES, Luís, 1997, Actores e Territórios Psicotrópicos: Etnografia das Drogas Numa Periferia Urbana. Porto, Faculdade de Psicologia e de Ciências da Educação da Universidade do Porto, tese de doutoramento.

FERNANDES, Luís, 1998, O Sitio das Drogas. Lisboa, Editorial Notícias.

FERNANDES, Luís, 2002a, "Acteurs et territoires 'psichotropiques': ethnographie des drogues dans une périphérie urbaine”, Déviance et Societé, 26 (4): 427-441.

FERNANDES, Luís, 2002b, "Um diário de campo nos territórios psicotrópicos”, em T. Caria (org.), Experiência Etnográfica em Ciências Sociais. Porto, Afrontamento, 23-40.

FERNANDES, Luís, Tiago NEVES, e Miguel CHAVES, 2001, "Investigação etnográfica em territórios psicotrópicos: notas de terreno e comentário", Educação, Sociedade e Culturas, 16: 171-201.

FERNANDES, Luís, e Alexandra RAMOS, 2010, "Exclusão social e violências quotidianas em 'bairros degradados': etnografia das drogas numa periferia urbana”, Toxicodependências, $16(2): 15-29$.

FERNÁNDEZ GONZÁLEZ, Miquel, 2014, Matar al "Chino": Entre la Revolución Urbanística y el Asedio Urbano en el Barrio del Raval de Barcelona. Barcelona, Universitat de Barcelona, tese de doutoramento.

FIRTH, Raymond, 1936, We, the Tikopia. Londres, George Allen and Unwin.

FIRTH, Raymond, 1959, Social Change in Tikopia. Londres, George Allen and Unwin.

FREEMAN, Derek, 1983, Margaret Mead and Samoa: The Making and the Unmaking of an Anthropological Myth. Cambridge, MA, Harvard University Press.

HERNÁNDEZ, Alicia, 2010, Oscar Lewis, Una Historia Cultural: Análisis Historiográfico de Los Hijos de Sánchez. México, DF, Universidad Autónoma Metropolitana, dissertação de doutoramento.

HUTCHINSON, Sharon, 1996, Nuer Dillemas: Coping with Money, War, and the State. Berkeley, University of California Press.

KUSENBACH, Margarethe, 2003, "Street phenomenology: the go-along as ethnographic research tool”, Ethnography, 4 (3): 455-485.

LE MARCIS, Frédéric, 2004, “The suffering body of the city", Public Culture, 16 (3): 453-477.

LEWIS, Oscar, 1963 [1951], Life in a Mexican Village: Tepotzlán Restudied. Urbana, University of Illinois Press.

LYOTARD, Jean-François, 1979, La condition post-moderne. Paris, Les Editions de Minuit.

MALINOWSKI, Bronislaw, 1961 [1922], Argonauts of the Western Pacific. Nova Iorque, E. P. Dutton.

MATA, Simão, e Luís FERNANDES, 2016, "A construção duma política pública no campo das drogas: normalização sanitária, pacificação territorial e psicologia de baixo limiar", Global Journal of Community Psychology Practice, 7 (1S): 1-25.

PAGÁN, Ginés, 1980, “La fábula de Alcalá y la realidad histórica en Grazalema: replanteamiento del primer estudio de antropología social en España”, Revista Española de Investigaciones Sociológicas, 9: 81-115.

PINA-CABRAL, João de, 2000, “The ethnographic present revisited”, Social Anthropology, 8 (3): 341-348. 
PINTO, José Madureira, 2008, "Ir e voltar a Fonte Arcada: considerações sobre a prática da razão sociológica”, em José Madureira Pinto (org.), Ir e Voltar: Sociologia de Uma Colectividade Local do Noroeste Português (1977-2007), Porto, Instituto de Sociologia da Faculdade de Letras da Universidade do Porto, relatório final de projeto, 8-17, disponível em < https://repositorio-aberto.up.pt/bitstream/10216/9192/2/irevoltarrelatriofinal000064517.pdf > (última consulta em junho de 2018).

PITT-RIVERS, Julian 1971 [1954], The People of the Sierra. Chicago, The University of Chicago Press.

POWELL, H.A., 1960, "Competitive leadership in Trobriand political organization", The Journal of the Royal Anthropological Institute of Great Britain and Ireland, 90: 118-145.

SPRADLEY, James, 1979, The Etnographic Interview. Belmont, Wadsworh Group.

SZTUTMAN, Renato, 1998, "Nós, os tikopias: um estudo sociológico do parentesco na Polinésia primitiva", Revista de Antropologia, 41 (2): 245-252.

TOBÓN, Marco, 2015, “Los sueños como instrumentos etnográficos”, Revista de Antropología Iberoamericana, 10 (3): 331-353.

WEINER, Annette, 1976, Women of Value, Men of Renown: New Perspectives in Trobriand Exchange. Austin, The University of Texas Press.

WHITE, William, 1993 [1943], Street Corner Society: The Social Structure of an Italian Slum. Chicago, The University of Chicago Press.

YARLYKAPOV, Akhmet, 2007, "Dreams of an ethnographer (an attempt at autoethnographic analysis)", Anthropology \& Archeology of Eurasia, 46 (2): 34-41.

ZAluAR, Alba, 1985, A Máquina e a Revolta: As Organizações Populares e o Significado da Pobreza. São Paulo, Editora Brasiliense.

ZIVKOVIC, Marko, 2006, "Sueños dentro-fuera: algunos usos del sueño en la teoria social y la investigación etnográfica”, Revista de Antropologia Social, 15: 139-171. 